\title{
Review of Municipal Solid Waste Processing Technologies-Indian Perspective
}

\author{
Mr. Nilesh C. Pratapwar ${ }^{1}$, Dr. Arif Khan ${ }^{2}$ \\ ${ }^{I} M$ Tech Environmental Engineering Pursuing, ${ }^{2}$ Principal \\ Nuva College of Engineering \& Technology, Nagpur, India, Pin 441501
}

DOI: 10.46335/IJIES.2020.5.8.5

\begin{abstract}
Municipal solid waste management (MSWM) has emerged as a big challenge not only because of the health and environmental concerns but also due to huge quantities of waste generated. It is observed from many research documents that most urban local bodies (ULBS) in India are unable to handle such huge quantities of solid waste due to financial and institutional weakness. ULBs rarely have sufficient funds, resources, infrastructure and appropriate strategies for improved solid waste management. Segregation of waste, door to door waste collection, technologies for the treatment of waste, land resources and scientific disposal methods are some of the major challenges.

Every year, the average citizen of a developed country produces about half tone of waste, thus waste management is an essential industry. This paper deals with the solid waste management available methods and practices in India. The solid waste management consist of various types of waste like industrial, agricultural, transport, radioactive, municipal etc. Although all types of wastes are harmful but municipal solid waste "now known as solid waste" is the type of waste which can be managed properly without causing any pollution and harm to other species. In this paper main focus is on Municipal solid waste. Various methods have been described to manage the solid waste from organic compost making to energy generation.
\end{abstract}

Keywords- MSW-treatment; MSW-methods; land resources

\section{I- INTRODUCTION}

$\mathbf{R}$ apid urbanization, urban growth and economic development have not only changed the physical size of the cities but also excreting significant additional pressure on the infrastructure services across Indian cities. India is experiencing high urbanization, currently 31 percentage as per census 2011 , contributing to 11 percent of the world population and having 53 metropolitan cities which may jump to 87 in 2031 . Urban growth is phenomenal and important for the development of the country. This rapid industrialization and population explosion in India has led to the migrant of people from villages to cities, which generate thousands of tons of MSW daily. The MSW amount is expected to increase significantly in the near future. These factors influence consumption rates that accelerate waste generation and change waste composition. The increasing trends in per capita waste generation puts immense pressure on urban local bodies (ULBs) who are mandated to provide this services in India. It is observed from the recent research that most ULBs are unable to handle such huge quantities of solid waste due to financial and institutional debilities. While daily collection efficiency is around 50-60 percent and 90 percent in few ULBs, only 10 percent of the collected waste receives treatment and virtually nothing is scientifically disposed in engineered landfills [10]. Indian cities are facing the problem of limited availability of land for waste disposal especially in large cities.

Open burning of MSW and landfill fires together releases 22,000 tons of pollutants in to the lower atmosphere of Mumbai city. The pollutants include Carbon Monooxide (CO), Carcinogenic Hydrocarbons (HC) (includes dioxins and furans), particulate Matter 
(PM), Nitogen Oxides (NO) and Sulphur dioxide (SO) [20]. Furthermore ULBs rarely have sufficient funds, resources, infrastructure and appropriate strategies which have resulted in poor collection, transportation, treatment and safe disposal of solids waste.

The present paper is an endeavor to provide a comprehensive review of the solid waste management system with technologies to treat them and most importantly highlight some major points require to overcome the challenges of municipal solid waste management in India. The paper contains majorly two parts first provides the comprehensive review of the current municipal solid waste management in India including the issues and key challenges faced by ULBs in making MSWM more sustainable and second will discuss the technological options available for the treatment and disposal of solid waste.

\section{II- CURRENT SCENARIO OF MUNICIPAL SOLID WASTE MANAGEMENT}

Solid waste management includes managing activities associated with collection, transportation, treatment and disposal of solid waste in an environmentally compatible manner with due consideration of the principles of economy, aesthetics, energy and conversation.

\section{II.1 Municipal Solid Waste Generation}

According to the Ministry of Environment and Climate Change in 2019 reply to question in Loksabha,[15] India Generated 1,50,000 tons per day(TPD) of municipal solid waste during 2016-2017, with an average waste generation of 0.115 $\mathrm{Kg} / \mathrm{Capita} / \mathrm{Day}$. It does not include waste picked up by kabadiwalas from households and from the streets by rag pickers. Whereas according to the report of the task force on waste to energy (2014) of the planning commission, the 7935 urban centers of India generated 1,70,000 TDP i.e. 62 million tons of MSW annually. It is observed that there is conflicting data about the actual quantum of waste generation in urban India because there is no system of periodically collecting data on waste generation. Modern urban living brings on the problem of waste because of everything in packing and fast food products which increases the quantity of waste and changes its composition with each passing day as is clear from Table- 1 .
Table-1 Waste Generation Trends in India

\begin{tabular}{ccc}
\hline Year & $\begin{array}{c}\text { Per Capita Waste } \\
\text { Generation } \\
\text { (Gm/Day) }\end{array}$ & $\begin{array}{c}\text { Total Urban MSW } \\
\text { Generation } \\
\text { (MT/Year) }\end{array}$ \\
\hline $\mathbf{1 9 7 1}$ & 375 & 14.9 \\
\hline $\mathbf{1 9 8 1}$ & 430 & 25.1 \\
\hline $\mathbf{1 9 9 1}$ & 460 & 43.5 \\
\hline $\mathbf{1 9 9 7}$ & 490 & 48.5 \\
\hline $\mathbf{2 0 2 5}$ & 700 & Double the amount of \\
\end{tabular}

Source- India Energy Portal [31]

In terms of per capita, the waste generation varies between 200-300 gms/capita for small towns, 300-400 gms/capita for medium cities and 400-600 gms/capita for large cities as per the planning commission report. The increase in waste quantities has been estimated at 5 percent per annum.it is assumed that urban India will generate 2,76,342 TPD by 2021, 4,50,132 TDP by 2031 and $11,95,000$ TDP of MSW by 2050 [11]. The physical and chemical characteristics of solid waste vary depending on population size and consumption pattern. As per the report, MSW constitutes 51 percent of organic waste followed by inert and non-organic waste at 32 percent. Plastic, paper and glass constitutes 17 percent of waste which are classified as recyclable wastes. The report of the earth engineering centre (2012) stated that the calorific value of the waste taken largely from 7 large metropolises varied between 6.8-9.8 Mj/Kg $(1620-2340 \mathrm{Kcal} / \mathrm{Kg})$. Waste from smaller cities have low calorific value mostly less than $800 \mathrm{Kcal} / \mathrm{Kg}$.It is Known that a calorific value of over $2800 \mathrm{Kcal} / \mathrm{Kg}$ is required for feasible incineration.

\section{II.2 Solid Waste Collection}

The report of the Planning Commission (2014) [11] shows that as high as 68 percent of the waste generated is collected daily in India while according to the report of MoUD (2011)[18], this percentage varies between the different sizes of cities, i.e. 70-90 percent in larger cities and less than 50 percent in smaller cities. It is observed that the collection efficiency of MSW in cities and towns is low due to non-uniformity in the collection system. Nearly 100 percent collection is observed in only those areas where the private contractors and NGOs are engaged in the waste collection activity. Uncollected waste often lies outside the designated bins in most of the urban areas due to inappropriate design, capacity, location and poor attitude of the community towards 
using bins. It is observed that the uncollected waste is generally burnt in open areas or on the streets. The report of the planning commission shows that over 81 percent of MSW annually is disposed at open dump sites without any treatment. Are port of Earth Engineering center shows that "such open burning of MSW and landfill fires together releases 22,000 tons of pollutants into lower atmosphere of Mumbai city every year".

It is worthwhile to note that the segregation of waste at the door step is almost absent although door to door waste collection is improving in some cities of India. Recognizing the need to adopt innovative strategies for sustainable solid waste management, many ULBs have started door to door waste collection, zero waste management, and segregation of waste at source in their cities.

Pune Municipal Corporation (PMC) has initiated door to door waste collection under $\mathrm{SWaCH}$ programme. In 2008, the PMC signed a five year Memorandum of Understanding to decentralize door to door collection services for households, shops, offices and small commercial establishments and to allow $\mathrm{SWaCH}$ members to carry out this work. As part of its support, the Corporation provides uniforms, aprons, raincoats and shoes for waste pickers involved in door to door waste collection as well as other equipment such as brooms and cycle rickshaws. At present, there are 2,300 waste pickers who collect garbage from 4 lakh properties with an average of 174 properties per waste picker. The Cooperative members collect user charges ranging between Rs.10/- to Rs.30/- per household per month from the service users. The advantage of $\mathrm{SWaCH}$ model is that it helps the PMC collect waste from door step, is cost effective, leads to high-resource recovery, is labour-friendly using existing workers and is a sustainable enterprise [10].

In Nagpur, a door to door waste collection system by a private operator introduced in 2008 [13] has been successful. The system is operated on a PPP model with a 10 year concession period. The operator uses closed body vehicles equipped with vehicle tracking system, same as which was introduced in Surat on 2004.

\section{II.3 Transfer Station and Transportation}

Transfer stations are used where disposal sites are more than $10 \mathrm{~km}$ away from the city. To save transportation time and fuel such cities have a good performance record of vehicle maintenance and adequate facilities to maintain large size vehicles and containers. Ramp facility is provided to facilitate uploading of the dumper placer containers directly into a large container at the transfer stations. If there is an issue of suitable land for a permanent station then mobile compactor truck with primary collection vehicles can be used to improve the transportation efficiency of the system [7]. Such stations have been effectively used in Nagpur [13], and Coimbatore. There are nine transfer stations in Nagpur and all are operational. Waste collected is transported to transfer stations through private vehicles and finally sent to the disposal site for waste disposal. Containers are fully closed with leak proof doors. The achievements of the transfer station model are (i) the municipal waste received through closed vehicles are dropped into closed containers with or without secondary handling; (ii) covered leak proof containers prevent spillage of waste on the road; (iii) no permanent or temporary storage at transfer stations, thus averting the nuisance of flies and animals at transfer stations; and (iv) separate leachate collecting system is provided

At present, although there are different types and sizes of vehicles used for transportation of waste such as dumper placers/schiff loaders, refuse collector without compactor, refuse collection mobile compactors, mini truck with tipping floor, hook loader/hook lifter, the selection of the type of vehicles depends on various factors such as the quantity of waste, distance, road widths and conditions and process technologies. To save travel time, minimize human errors and improve the monitoring system, many ULBs have installed Global Positioning System (GPS), Geographic Information System (GIS), and Global System for Mobile Communication (GSM) system in their trucks to collect waste from secondary sources for the disposal of waste. The Tool Kit for Solid Waste Management prepared by the MoUD reveals that municipalities like Pimpri- Chinchwad, Hyderabad and Delhi have benefitted from this system. Ensuring the efficiency of 100 percent waste collection is still a big challenge for the ULBs despite these technologies. Another significant challenge is to deal with corruption and lack of commitment in the solid waste transport sector

\section{III-Technology for Treatment of Solid Waste}

The hierarchy of waste management is reducing the use of material and reusing them to be the most environmental friendly. Source reduction begins with reducing the amount of waste generated and reusing materials to prevent them from entering the waste stream [21].Thus, waste is not generated until the end of "reuse" phase. Once the waste is generated, it needs to be collected. Material recovery from waste in the form of 
recycling and composting is recognized to be the most effective way of handling wastes.

At present, there are a number of processing technologies such as composting, bio-methanation, recycling, refuse derived fuel (RDF), gasification, incineration, pyrolysis, engineered landfills etc., available for the treatment of municipal solid waste. However, each of the technologies may have positive as well negative implications. The selection of suitable technologies depends on the population of a city and quantity of waste. It is important to note that "the biggest constraints lie in separating, collecting and transporting this component to the location where decentralized or centralized large scale composting or biogas generation plus composting can be carried out" (Mani,2015).Efficiency of recycling and composting is greatly reduced due to the absence of source separation

\section{III.1- CPHEEO Manual on Municipal Solid Waste Management}

As per CPHEEO the solid waste management processing technology suggested as follow selection of technology are based on various parameter and criteria.

- Windrow composting

- Vermiculture

- Biomethanation

- $\quad$ Refuse Derived Fuel (RDF)

- Incineration

- Integrated System (Composting +RDF)

- Sanitary Landfill

\section{III.2- Technologies for MSW}

There are various classification of technologies based on their function or type of solid waste for which that specific technology is required. Such as

- Biological Methods under which composting technology comes,

- An-aerobic digestion under which Biogas technology comes,

- Physico-chemical methods under which combustion, open burning, sterilization with volumetric reduction, pyrolysis and gasification comes.

Further these technologies are classified or categorized based on their processing mechanism as follow

- Thermal processing Technologies

- Mass-burn Incinerations

○ Pyrolysis/Gasification
- Plasma Arch Gasification

- Biological Processing Technologies

○ Composting(Aerobic Process)

- Bio-methanation (Anaerobic process)

- Physical process technologies

○ Refuse Derived Fuel (RDF)

- Combination Technologies (MBT)

- Mechanical Biological Treatment

Mass-burn Incinerations: Mass-burn systems are the predominant form of MSW incineration. It involves combustion of unprocessed or minimally processed refuse. The major components of a mass-burn facility include: (1) Refuse receiving, handling, and storage systems; (2) Combustion and steam generation system (a boiler); (3) Flue gas cleaning system; (4) Power generation equipment (steam turbine and generator); (4) Condenser cooling water system; and (5) Residue hauling and storage system.

Mass-burn incineration with a movable grate incinerator is a widely used and thoroughly tested technology. It meets the demands for technical performance and can accommodate large variations in waste composition and calorific value. A less common mass burning alternative is the rotary kiln.

The main advantage of a mass-burn facility is the amount of energy that it produces. However, it does have the disadvantage of producing significant amounts of air pollution, including heavy metals released during the combustion process. The ash that results from the combustion still has to be disposed. In considering the MSW incineration option, it is important to weigh the benefits of incineration against the significant capital and operating costs, potential environmental impacts, and technical difficulties of operating an incinerator.

Gasification: The gasification process involves the partial oxidation of carbon-based feedstock to generate a syngas, which can be used as a fuel or for the production of chemicals. Gasification produces gases and liquids, as well as residual solids, including ash and carbon char. Inorganic materials in the feedstock are removed as bottom ash. They are usually combined with char, and can be separated out for disposal or used in making block materials.

Gasification typically relies on carbon-based waste such as paper, petroleum-based wastes such as plastics, and organic materials such as food scraps. As MSW is a heterogeneous waste stream, pre-processing of MSW is required to make the gasification process more efficient. 
The pre-processing includes the separation of thermally non-degradable material such as metal, glass and inerts, along with size reduction and/or densification of the feedstock, if required. If MSW has high moisture content, a dryer may be added to the pre-processing stage to lower the moisture content of the MSW to $25 \%$ or less, because lower moisture content of the feedstock increases its heating value and the system becomes more efficient. The optimal calorific value of waste should be approximately $2000 \mathrm{kcal} / \mathrm{kg}$ for proper gasification.

Pyrolysis: Pyrolysis involves an irreversible chemical change brought about by the action of heat in an atmosphere devoid of oxygen. Synonymous terms are thermal decomposition, destructive distillation and carbonization. Pyrolysis, unlike incineration, is an endothermic reaction and heat must be applied to the waste to distil volatile components. The process of converting plastic to fuels through pyrolysis is possible, but yet to be proven to be a commercially viable venture.

Pyrolysis is carried out at temperature between 500 and $1000^{\circ} \mathrm{C}$ and produces three component streams.

- Gas: A mixture of combustible gases such as hydrogen, carbon monoxide, methane, carbon dioxide and some hydrocarbons.

- Liquid: Consisting of tar, pitch, light oil and low boiling organic chemicals such as acetic acid, acetone, methanol, etc.

- Char: Consisting of elemental carbon along with the inert materials in the waste feed.

The char, liquids and gas are useful because of their high calorific value. Part of the heat obtained by the combustion of either char or gas is often used as process heat for the endothermic pyrolysis reaction. It has been observed that even after supplying the heat necessary for pyrolysis, a certain amount of excess heat still remains which can be commercially exploited.

Bio-methanation (Anaerobic process): Biomethanation involves controlled biological degradation of organic waste by microbial activity in the absence of oxygen. The process involves the anaerobic (without air) decomposition of wet organic waste to produce a methane-rich biogas fuel and a small amount of residual sludge that can be used for making compost. It takes place in digester tanks or reactors, which enable the control of temperature and $\mathrm{pH}$ levels for optimizing process control. The methane-rich gas produced is suitable as fuel for energy generation. The residual sludge is also produced, which is suitable for enriching compost materials. Input preparation or source separation is required to ensure that waste is free of nonorganic contamination.

The yield of biogas depends on the composition of the waste feedstock and the conditions within the reactor. Modern anaerobic digestion treatment processes are engineered to control reaction conditions so as to optimize digestion rate and fuel production. Typically, $100-200 \mathrm{~m}^{3}$ of gas is produced per ton of organic MSW that is digested. The homogeneity of the feed material is an important parameter from the efficiency point of view. The waste must be sorted so that all inorganic products are removed from the refuse prior to entry into the digester. Ideally the refuse should be sorted at source. If not, it could be sorted by hand/mechanical means on delivery to the site.

The solid waste management system needs to be modified and improved to make it compatible with the requirements of bio-methanation technology covering source separation collection of solid waste. Otherwise, the applicability will be limited to highly organic and homogenous waste streams such as slaughterhouse waste, market waste.

Composting: Composting is a simple biological process in which controlled aerobic biological decomposition of organic matter by microorganisms (mainly bacteria and fungi) takes place to produce a stable humus-like product.

The process is controlled so that it is managed with the aim of accelerating decomposition, optimizing efficiency, and minimizing any potential environmental or nuisance problems that could develop. The microbes, fungi, and macro-organisms that contribute to this biological decomposition are generally aerobic. The composting of the waste generally yields $15-20 \%$ compost. The high organic content in the municipal waste stream is ideal for composting.

The size and configuration of the composting plant depends upon the quantity of materials to be processed and the duration of activities, including active composting, curing, and storage. The typical duration for composting is 45 to 60 days, while curing or maturation requires 30 to 120 days, and storage is dependent on the amount of time until the product can be marketed or removed for use. 
There are two fundamental types of composting techniques: open or windrow composting, which is done out of doors with simple equipment and is a slower process; and enclosed system composting, where the composting is performed in a building, a tank, a box, a container or a vessel.

The turned windrow system is the technique most readily associated with the large-scale composting of wastes. A windrow is a pile that is generally $1.5-2$ times as wide as its height, with its length determined by the amount of material available. Windrows are generally placed parallel to one another, with enough room in the middle for turning and power equipment to pass through. Windrow composting processes are simpler, require less capital, and use less energy. They generally rely more on land and labour and less on machinery.

In-vessel systems, such as drum or agitated bed technologies, or any technical system enclosed in a building, require complex equipment. These systems are highly engineered, capital intensive and require day-to-day management due to their automated systems and design, which has necessarily incorporated mitigation of potential worker health, environmental impact and nuisance conditions. They also use substantial amounts of energy. Composting is the most commonly used waste processing technology internationally and the cost varies significantly depending upon the extent of mechanization, labour costs, and quality of input waste

Refuse Derived Fuel: The term "refuse-derived fuel" (RDF) describes MSW that has been processed to a fairly uniform fuel for combustion. The RDF process typically includes thorough pre-separation of recyclables, shredding, drying, and densification to make a product that is easily handled. Glass and plastics are removed through manual picking and by commercially available separation devices. This is followed by shredding to reduce the size of the remaining feedstock to about eight inches or less, for further processing and handling. Magnetic separators are used to remove ferrous metals. Eddy-current separators are used for aluminum and other non-ferrous metals. The resulting material contains mostly food wastes, non-separated paper, some plastics (recyclable and non-recyclable), green wastes, wood, and other materials. Drying to less than $12 \%$ moisture is typically accomplished through the use of forced-draft air. Additional sieving and classification equipment may be utilized to increase the removal of contaminants.

The RDF can be immediately combusted on-site or transported to another facility for burning alone, or with other fuels. It can be used in waste-to-energy plants as the primary or supplemental feedstock, or co-fired with coal or other fuels in power plants, in kilns of cement plants, and with other fuels for industrial steam production. Generally, 100 TPD generates $1 \mathrm{MW}$ of power through RDF incineration route

One of the first waste-to-energy plant based on RDF technology was setup in Hyderabad in 1999. It was set up through technology transfer by the Andhra Pradesh Technology Development \& Promotion Centre (APTDC), TIFAC and SELCO International Ltd. The installed capacity of the MSW processing plant was 700

TPD and it could manufacture 200-250 TPD of RDF fluff. The power plant based on RDF was started in November 2003 at Shadnagar, about $50 \mathrm{~km}$ from the processing plant. The Power Plant was using a high percentage of biomass as support fuel for combustion of the RDF. The power generated was exported to the APTRANSCO Grid. Frequent breakdowns in the grate led to the closure of the power plant operations.

As per secondary sources, there were about 25-30 operating RDF processing plants in India in year 2014, with an installed capacity of about 3,395 TPD[ ].

Mechanical Biological Treatment (MBT): Mechanical Biological Treatment (MBT) is a combination of technologies including material recovery facilities, refuse derived fuels and aerobic/anaerobic digestion. The selection of technologies in MBT is dependent upon the waste characteristics i.e. High/low percentage of organics/inerts/recyclables and moisture content. The MBT technology aims at reduction in the percentage of inerts to be disposed of at landfills.

Mechanical biological treatment has no/minimal demand for source segregation of waste. The technology is suitable to handle high/low organic waste with high/low moisture content. The flexibility in the technology allows better adaptation to changing waste quantities and qualities than mass burn incineration. In this technology, the organics i.e. highly putrescible waste is recovered to generate biogas and high calorific value waste is segregated for preparation of Refuse Derived Fuel (RDF). The initial waste preparation includes removal of any bulky objects like boulders, mattress, tree branches which may hinder the proper functioning 
of the equipment further down the line. The size reduction and separation techniques includes shredding/disc separator/ballistic separator followed by recovery of high value recyclables/fuel and aerobic/anaerobic digestion of organic waste in water to generate biogas.

The technology is internationally proven and is more acceptable among the public. MBT process configurations can vary significantly and can be designed to suit local market conditions. For e.g. if RDF is not saleable/easily marketable then it can be combusted to generate energy

\section{IV- TECHNOLOGY SUSTAINABILITY PARAMETERS}

Technology that requires value addition of MSW chain for sustainability against following parameters.

- Technology that can process mixed waste.

- Technology that requires pre-processing of waste to make it compatible.

- Technology that requires source segregated waste and a higher degree of pre-processing.

- Compliance with the regulatory requirement

- Rejects diversion to landfill, means technology with low diversion of rejects to the landfill or more acceptable.

- Social acceptability

- Market for products and by-products.

- Low Carbon foot print.

- Modular and flexible plant to address the increase waste supply in future.

\section{V- CONCLUSION}

The weakest points of centralized waste management system are the transportation of waste to large processing facilities, and the complex waste separation systems required. Both of them are energy intensive, thus contribute to the deepening of climate change. Additionally, they increase the cost borne by public. Garbage treatment in households offers the opportunity to eliminate the inconvenience of extend waste management systems. At a domestic level several waste management system may be applied depending upon available space, time and the financial resources of the householders. Unfortunately, most of them allow the processing of only organic waste.

MBTs are complex waste treatment plants with a wide ranging variety in terms of their technical configuration. Most of the processes subsumed under the generic term mechanical biological treatment have proven their functional capability - despite of the short period of development. In many cases various development stages, usual in process engineering, were skipped. Therefore it does not astonish, that during the years of their development the MBT plants had to scope with various problems, which meanwhile are partly solved and partly still subject of optimization.

\section{REFERENCES}

[1] Census of India, 2011, General Population Table.

[2] Earth Engineering Centre, (2012), 'Sustainable Solid Waste Management in India', RanjithKharvelAnnepu, Columbia University, NewYork, January.

[3] GesellschaftfurI nternationale Zusammenarbeit (GIZ), 2015, 'Salient Features of the MSWM Manual: An Overview', Part I, Training on Municipal Solid Waste Management, organized by GIZ and German Cooperation, Ministry of Urban Development, at New Delhi on May 5-8, 2015.

[4] Gupta, P. T., (2015), Whither Indian Urban Growth: Dreams and Reality of Healthy Urban City in India, CITIES: The 21st Century India, edited by Satpal Singh, Bookwell, New Delhi.

[5] Mani, S., (2015), Technologies for Centralized Solid Waste Management, CITIES: The 21st Century India, edited by Satpal Singh,Bookwell, New Delhi.

[6] Ministry of Urban Development, (2014), 'Draft of Municipal Solid Waste Management Manual', Central Public Health and Environmental Engineering Organization (CPHEEO), Ministry of Urban Development, Government of India, New Delhi, May.

[7] Ministry of Urban Development, (2012), 'Toolkit for Solid Waste Management' - Jawaharlal Nehru National Urban Renewal Mission (JnNURM), Ministry of Urban Development, Government of India, New Delhi November.

[8] Ministry of Urban Development, (2011), the High Powered Expert Committee (HPEC) for Estimating the Investment Requirements for Urban Infrastructure Services: Report on Indian Urban Infrastructure and Services, Ministry of Urban Development, Government of India, March.

[9] Ministry of Urban Development, (n.a.), Guidance Note: 
Municipal Solid Waste Management on a Regional Basis, Foreword: Secretary, Ministry of Urban Development, Government of India, New Delhi.

[10] National Institute of Urban Affairs, (2013), National Workshop on Sustainable Solid Waste Management in India: Workshop Proceedings, organized by Ministry of Urban Development, GoI, Ministry of Environment \& Forest, GoI and National Institute of Urban Affairs, New Delhi, 18 January 2015.

[11] Planning Commission,(2014), 'Report of the Task Force on Waste to Energy', Vol. I, Planning Commission, New Delhi, May.

[12] H. Jouhara et al. /Energy 139 (2017) 485-506 Municipal waste management system for domestic use.

[13] Report_IN_Nagpur_SolidWasteManagement_Arcadis GermanyGmbH_2017.

[14] ShyamalaManiand Satpal Singh/Procedia Environmental Sciences $35 \quad$ (2016)150-157 Sustainable Muncipal Solid Waste Management in India: A Policy Agenda.

[15] Loksabha unstarred question no 4553 to be answered on 19.07.2019 by Ministry of environment, Forest and Climate Change.

[16] Vandana Bhari, Jaspal Singh and A.P. Singh- A Review on Solid Waste Management Methods and Practices in India-Trends in Biosciences 10 (21), 2017.

[17] Sharma, S., Shah, K.W., 2005. "Generation and disposal of solid waste in Hoshangabad". In: Book of Proceedings of the Second International Congress of Chemistry and Environment, Indore, India, 749 751.

[18] Shekdar, A.V., 1999. Municipal Solid Waste Management - the Indian perspective. Journal of Indian Association for Environmental Management 26 (2): 100- 108.

[19] Studies on Environmental Quality in and around Municipal Solid Waste Dumpsite. Arun K. Biswas, Sunil Kumar, S. Sateesh Babu, J.K. Bhattacharyya, Tapan Chakrabati. 2, Kolkata, Nagour: Resources, Conservation and Recycling, 2010, Vol. 55 .

[20] National Environmental Engineering Research Institute, NEERI. Air Quality Asses sment, Emis sions Invent ory and Sour ce Apportionment Studies: Mumbai. New Delhi: Central Pollution Control Board (CPCB), 2010.

[21] Perinaz Bhada, Nickolas Themelis. Feasibility Analysis of Waste- to-Energy as a Key Component of Integrated Solid Waste Management in Mumbai, India. New York: Earth Engineering Center, Waste-to-Energy Research and TechnologyCouncil, 2008.

[22] Hennepin Energy Recovery Center, HERC. More Power than You Know. Inspector America, History Channel.

[23] Kumar, Sunil. Municipal Solid Waste Management in India: Present Practices and Future Challenge. Clean Development Mechanism, United Nations Framework Convention on Climate Change.

[24] The Use of Compost: its Effects on Heavy Metal Levels in Soil and Plants. F. Pinamonti, G. Stringari, F. Gasperi, G. Zorzi. 2, s.l.: Resources, Conservation and Recycling, 1997, Vol.21.

[25] Kant, Ravi. Managing Director, Ramky Enviro Engineers Ltd.January 2011.

[26] A.Gendebien, A. Leavens, K. Blackmore, A. Godley, K. Lewin, K.J.Whiting, R.Davis, J.Giegrich, H. Fenhrenbach, U. Gromke, N. del Bufalo, D. Hogg. Refuse Derived Fuel, Current Practice and Perspectives. Environment, European Commission. July 2003.

[27] Bureau of Land \& Waste Management, Division of Mining \& Solid Waste Management. Regulation 67107.12, SWM: Solid Waste Incineration and Solid Waste Pyrolysis Facilities. South Carolina Department of Health and Environmen tal Control. May 28, 1999.

[28] Department of Economic Affairs, Ministry of Finance, Government of India. Position paper on the solid waste management sector in India. Public private partnerships in India. November 2009.

[29] Sustainable Recycling Model: A Comparative Analysis between India and Tanzania. Bob Jan Schoot Uiterkamp, Hossein Azadi, Peter Ho. 3, s.l: Resources, Conservation and Recycling, 2011, Vol.55.

[30] Urban Development Sector Unit, East Asia and Pacific Region, The World Bank. What a Waste: Solid Waste Management in Asia. Environmental Strategies for Cities, Massachusetts Institute of Technology. 1999.

[31] Dimpal Vij /Procedia-Social and Behavioral Sciences 37 (2012) 437-447-Urbanization and Solid waste Management in India: Present Practices and Future Challenges.

[32] Manual on Municipal Solid Waste Management by CPHEEO. 